\title{
Abnormal Adrenal Steroidogenesis in Growth-Retarded Newborn Infants
}

\author{
C. RICHARD PARKER, JR., E. STEPHEN BUCHINA, AND THOMAS K. BAREFOOT \\ Department of Obstetrics and Gynecology, University of Alabama at Birmingham, Birmingham. \\ Alabama $35233-7333$
}

\begin{abstract}
The results of prior studies suggest that abnormalities of development and function of the fetal adrenal occur in pregnancies complicated by intrauterine fetal growth retardation (IUGR). In the present investigation, we sought to extend such studies by matching IUGR infants with normally grown infants of women in whom pregnancy complications, delivery method, and gestational age were comparable. In 47 vaginally delivered, IUGR infants $(38 \pm 2$ wk, mean \pm SD; $2244 \pm 589 \mathrm{~g}$ body weight), the levels of dehydroepiandrosterone sulfate (DS) in umbilical cord serum $(4.48 \pm 2.94 \mu \mathrm{mol} / \mathrm{L})$ were lower $(p=0.035)$ than those $(5.94 \pm 3.63 \mu \mathrm{mol} / \mathrm{L})$ of 47 normal weight infants $(38 \pm 2$ wk; $3107 \pm 527$ g). Yet, umbilical cord serum levels of cortisol in IUGR infants $(455 \pm 189$ nmol/L) were slightly higher than those of the control infants $(408 \pm 247 \mathrm{nmol} / \mathrm{L})$. The $\mathrm{DS} /$ cortisol molar ratio in IUGR infants $(10.5 \pm 6.8)$ was $41 \%$ lower $(p=0.0013)$ than that of the control infants $(17.7 \pm 13)$. Also, the estimated DS plasma pool in IUGR infants $(521 \pm 349$ nmol) was strikingly lower $(p=0.0018)$ than that of the control infants $(800 \pm 480 \mathrm{nmol})$; the estimated plasma pools of cortisol were equivalent (growth-retarded: $53 \pm$ 27 nmol; control: $55 \pm 34$ nmol). Although we anticipated that total cholesterol and apo B levels in IUGR infants would be increased due to reduced adrenal utilization of LDL for DS production, such was not the case. We conclude that a selective deficiency of DS production occurs in the IUGR fetus. (Pediatr Res 35: 633-636, 1994)
\end{abstract}

\section{Abbreviations}

IUGR, intrauterine growth retardation or retarded DS, dehydroepiandrosterone sulfate PIH, pregnancy-induced hypertension

Estrogen production in human pregnancy is largely dependent on the production of DS by the fetal adrenals and subsequent aromatization of DS and 16 hydroxy-DS (formed in the fetal liver from DS) in the placenta. In normal fetuses, plasma DS concentrations seem to remain relatively constant during the latter half of gestation with the exception of a progressive rise during the last 6-8 wk of intrauterine life (1). Thus, the fetal plasma pool of DS increases steadily between approximately 20 and $32 \mathrm{wk}$ in concert with fetal growth and then increases strikingly near term (1), giving rise to the accelerated increase in estrogen production that occurs at this time $(2,3)$. In pregnancies complicated by IUGR, maternal estrogen levels are usually sub-

Received August 26, 1993; accepted January 18, 1994

Correspondence: C. Richard Parker, Jr., Ph.D., Department of Obstetrics and Gynecology, University of Alabama at Birmingham, UAB Station, Birmingham. AL 35233-7333.

Supported by NIH Grant HD22969. normal $(4,5)$. Impaired estrogen production in such circumstances could result from several factors, including reduced mass of the placenta wherein estrogen formation occurs and decreased adrenal production of DS by the growth-retarded fetus.

We $(3,6-8)$ and others $(9)$ have found subnormal DS concentrations in umbilical cord blood of infants believed to be stressed in utero as a consequence of various pregnancy complications. On the other hand, many such infants have normal to increased cortisol levels (6-8). Such findings are suggestive of stress-associated alterations in the adrenal steroid biosynthetic pathway. There is also evidence suggestive of reduced DS production and a divergence in the relative activity of the corticosteroid versus androgen pathway in the adrenals of IUGR infants during the first week of life $(10,11)$. In a more recent study, Reynolds $e t$ al. (12) found that IUGR infants had lower than normal levels of DS and estriol in umbilical cord blood at delivery. Interpretation of these latter data, however, is not completely straightforward, inasmuch as the control group consisted of uncomplicated pregnancies whereas the IUGR infants were delivered of women having a variety of pregnancy disorders, some of which might have independently altered fetal adrenal steroidogenesis $(3,6-9)$. There are, however, morphologic data that may be consistent with the aforementioned studies: the adrenals of IUGR infants often are disproportionately small, and there may be reduction of the fetal zone relative to the outer neocortex of such adrenals (13). The fetal zone seems to produce predominantly DS, whereas the neocortex primarily secretes cortisol (14).

On the basis of the results of studies in vitro (15), it seems likely that circulating cholesterol, particularly LDL cholesterol, serves as an important substrate for fetal adrenal steroidogenesis. In many circumstances $(3,6,7,16,17)$, fetal plasma levels of total cholesterol and LDL cholesterol are inversely related to plasma levels of DS, suggesting that the rate of utilization of plasma cholesterol for adrenal steroidogenesis may exert a significant effect on circulating levels of cholesterol. Because it has been noted that the liver of the IUGR fetus also is disproportionately small as a consequence of reduced numbers and cytoplasmic volume of hepatocytes (13) and apparently produces subnormal amounts of IGF-I (18), it is conceivable that deficiencies in hepatic production of LDL also could occur, giving rise to inadequate sources of precursor for fetal adrenal steroid production. To provide additional insights into adrenal function in the IUGR fetus, we conducted a study of vaginally delivered IUGR infants and normally grown infants in which gestational age and maternal pregnancy complications were comparable in both groups.

\section{MATERIALS AND METHODS}

The protocol for these studies was approved by the Institutional Review Board of the University of Alabama at Birmingham. Mixed umbilical cord serum was obtained at delivery of 47 singleton IUGR infants, below the 10th percentile of weight for gestational age (19), who were delivered vaginally between 31 
and 43 wk of gestation. Each IUGR infant was pair-matched with a normally grown (10th-90th percentile of weight), vaginally delivered singleton infant of similar gestational age $( \pm 1 \mathrm{wk})$; exact matches for gestational age were accomplished in all but nine pairs. We also matched as closely as possible for preexisting medical disorders and the pregnancy-associated complications noted in the IUGR group (Table 1). Preterm labor and delivery $(<37 \mathrm{wk})$ and postterm delivery ( $\geq 42 \mathrm{wk}$ ) were obstetric complications noted in several IUGR pregnancies. Among the IUGR pregnancies complicated by hypertension, five had mild PIH and one had severe PIH; among the pregnancies chosen as matches for IUGR, three had mild PIH and three had chronic hypertension. The diabetic pregnancies in each group were all class $A$. None of the IUGR or control infants had been exposed to exogenous glucocorticoids in utero. Umbilical cord sera from the matched pairs were assayed for DS and cortisol as described previously $(20,21)$; samples from such pairs were analyzed in the same assay run. Total cholesterol and apo B also were quantified in serum from many of these infants. Cholesterol was measured spectrophotometrically by use of the cholesterol HP reagent (Boehringer Mannheim Diagnostics, Indianapolis, IN). Apo B was measured by RIA in which the antibody was prepared in rabbits against human LDL. The assay standard was an adult human serum pool $(640 \mu \mathrm{g}$ apo $\mathrm{B} / \mathrm{mL})$ that was standardized against IUIS/WHO material CDC 1883; the radiolabeled ligand was ${ }^{125} \mathrm{I}$-apo B obtained from Ventrex Laboratories (Portland, ME). Precipitation of antibody-bound ligand was achieved with goat anti-rabbit gamma globulin (Clinetics, Tustin, CA). The useful range of the assay standard curve is $12.5-800 \mathrm{ng}$ at an antibody dilution of 1:12 000. Sera from a patient having homozygous hypobetalipoproteinemia are nonreactive in the assay. The results that we obtained with this assay on fetal and adult human sera are comparable to those derived from use of a previously available commercial assay kit (Ventrex Laboratories). All data are presented as the mean \pm SD. The data were analyzed by two-tailed $t$ test, and a $p$ value $<0.05$ was considered statistically significant.

\section{RESULTS}

Although the birth weights of the IUGR infants $(2244 \pm 56 \mathrm{~g}$; mean \pm SEM) were significantly lower $(p<0.0001)$ than those of the control infants $(3107 \pm 77 \mathrm{~g})$, the gestational ages of the two groups were identical $(38.0 \pm 0.3 \mathrm{wk})$. Five of the IUGR infants and one of the control infants had umbilical arterial $\mathrm{pH}$ $<7.15$. Only one infant, a 37 -wk IUGR newborn whose $\mathrm{pH}$ was 6.78, had a 5-min Apgar $<7$.

Umbilical cord serum levels of DS in the IUGR infants ranged from 0.46 to $11.55 \mu \mathrm{mol} / \mathrm{L}$ and were significantly lower $(p=$ 0.035 ) than those of the control infants, which ranged from 0.76 to $17.53 \mu \mathrm{mol} / \mathrm{L}$ (Fig. 1). On the other hand, the mean umbilical cord serum levels of cortisol were slightly higher in the IUGR infants (range $=157-974 \mathrm{nmol} / \mathrm{L}$ ) than in controls (range = $146-1415 \mathrm{nmol} / \mathrm{L})$. The DS/cortisol molar ratio in umbilical cord serum of the normal infants was almost twice that of the IUGR infants $(p=0.0013)$. The apparent shift in adrenal steroidogenesis seen in the entire group of IUGR infants (reduced DS and slightly increased cortisol concentrations) that gave rise to the marked reduction in the DS/cortisol ratio also was noted

Table 1. Pregnancy complications of IUGR and control study groups

\begin{tabular}{lccccc}
\hline & Hypertension & Diabetes & Preterm & Postterm & Other* \\
\hline $\begin{array}{c}\text { Growth retar- } \\
\begin{array}{c}\text { dation } \\
\text { Control }\end{array}\end{array}$ & 6 & 1 & 10 & 4 & 8 \\
\hline
\end{tabular}

* Other includes drug abuse, premature rupture of membranes, amnionitis, renal failure, incompetent cervix, Crohn's disease, $\mathrm{Rh}$ isoimmunization, chicken pox, neurofibromatosis, and seizure disorder.

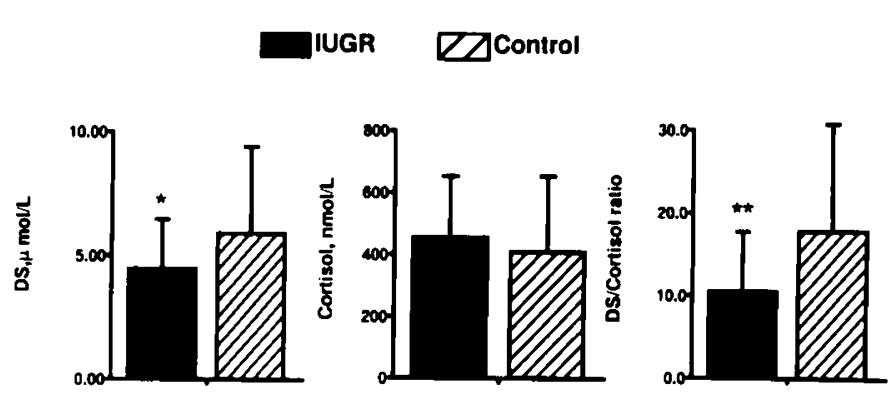

Fig. 1. The effect of IUGR on umbilical cord serum levels of DS, cortisol, and the DS/cortisol ratio at birth. The data are plotted as mean $\pm \mathrm{SD}$. To convert to metric units: $\mathrm{DS} \div 2.714=\mu \mathrm{g} / \mathrm{mL}$; cortisol +27.59 $=\mu \mathrm{g} / \mathrm{dL} .{ }^{*}, p<0.05 ;{ }^{* *}, p<0.005$.

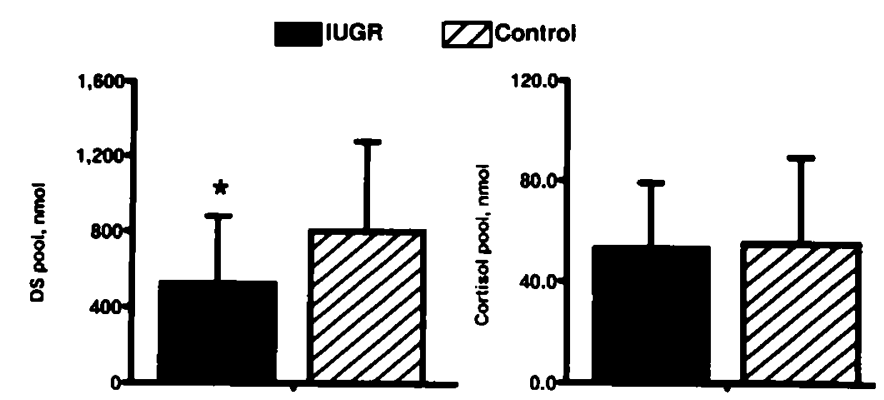

Fig. 2. The effect of IUGR on the estimated plasma pool size of DS and cortisol. The data are plotted as mean \pm SD. See text for details. ${ }^{*}$, $p<0.005$.

when we subdivided the infant groups according to whether the pregnancies were complicated or not. The DS/cortisol ratio in the IUGR infants delivered at term (37-41 wk) of women having no complications $(10.0 \pm 7.38$, mean \pm SD) was lower $(p=$ $0.0073)$ than that in their control group $(18.3 \pm 11.02)$. The DS/ cortisol ratio of IUGR infants of women having pregnancy complications (preterm or postterm delivery, medical complications, or both) was $11.2 \pm 7.89$, which also was lower than, although not statistically different from $(p=0.080)$, that of the non-IUGR control group of infants delivered of women having similar complications during pregnancy $(17.3 \pm 15.64)$.

To place the resulting hormone data in greater perspective, we also estimated the plasma pools of DS and cortisol in each infant. Plasma volumes were assumed to be $46.8 \mathrm{~mL} / \mathrm{kg}$ for normally grown preterm infants, $43.1 \mathrm{~mL} / \mathrm{kg}$ for normally grown term infants, and $52.0 \mathrm{~mL} / \mathrm{kg}$ for IUGR infants (22). The plasma pool was calculated as the product of the serum concentration and the plasma volume. The resulting data are likely to be minimal estimates, inasmuch as they do not take into account the total volumes of distribution, which may exceed the plasma volume. The estimated plasma DS and cortisol pools of the IUGR infants and the control infants are shown in Figure 2. The DS pool of the IUGR infants was significantly lower $(p=0.0018)$ than that of the group of matched control infants. The difference in the DS pools between the two groups $(280 \mathrm{nmol} ; 103 \mu \mathrm{g})$ represents a $35 \%$ reduction in the IUGR group compared with the normally grown infants. On the other hand, despite the substantial differences in body weights, the cortisol pools of both groups were comparable, being $\leq 10 \%$ of the DS pool in IUGR and normalweight infants.

Total serum cholesterol levels in the IUGR infants $(1.57 \pm$ $0.53 \mathrm{mmol} / \mathrm{L}, n=44 ;$ range $=0.46-2.99 \mathrm{mmol} / \mathrm{L})$ were slightly, but not significantly, lower $(p=0.087)$ than those in the control group $(1.76 \pm 0.41 \mathrm{mmol} / \mathrm{L}, n=46 ;$ range $=0.46-2.66 \mathrm{mmol} /$ L). The apo B levels in IUGR infants $(285 \pm 163 \mu \mathrm{g} / \mathrm{mL}, n=$ 23 ; range $=59-718 \mu \mathrm{g} / \mathrm{mL}$ ) were similar to those in the control infants $(309 \pm 172 \mu \mathrm{g} / \mathrm{mL}, n=31$; range $=150-625 \mu \mathrm{g} / \mathrm{mL})$. The wide range in lipoprotein and steroid concentrations noted among these infants was anticipated in view of the range of 
gestational ages and the considerable variety of pregnancy conditions included in our study population.

\section{DISCUSSION}

In normal human pregnancy, high rates of estrogen production are maintained by placental aromatization of the large quantities of DS produced by the fetal adrenals. The most striking chronic reductions in estrogen production, apart from that caused by fetal death, are associated with placental sulfatase deficiency, fetal anencephaly, and IUGR (3-5). Whereas the two former situations are relatively simple to explain in relation to their impact on estrogen production, function of the fetoplacental unit in IUGR is less clear.

If DS and cortisol concentrations in the IUGR infants were normal, then one could conclude that the pituitary-adrenal axis of the IUGR infants was operating normally and the reduced estrogen production seen in such pregnancies occurs largely as the result of a simple fetal size-associated reduction in total estrogen precursor available for aromatization. In the present study, however, we found evidence for a significant deficit in production of DS and no change or possibly a slight increase in cortisol formation by the adrenals of IUGR infants. The net effect of these changes was a nearly $50 \%$ reduction in the DS/ cortisol molar ratio in umbilical cord blood of IUGR infants compared with a carefully selected group of normal-weight infants. Our results, therefore, are compatible with those of Reynolds and associates $(10-12)$, who also have provided evidence for a reduction in DS production, possibly in the absence of impaired cortisol secretion by the fetal adrenals. Selective deficiencies in fetal adrenal DS production in the IUGR infant would be consistent with findings in other groups of infants believed to be severely stressed in utero (6-9). Such data suggest that development of the fetal zone of the fetal adrenal, function of the DS biosynthetic pathway, or both are inhibited by many complications of pregnancy. There are also morphologic findings to support this view $(13,23)$. On the other hand, the cortisol pathway, which seems to prevail in the neocortex (14), seems to be either unaffected or stimulated in circumstances of fetal stress (6-8). Until the factor or factors that are responsible for the functional and morphologic zonation of the human fetal adrenal during normal development are defined, the mechanism that may be common to many pregnancy disorders and leads to disturbances in the growth and function of the fetal adrenals also will remain unresolved. It seems reasonable to assume, however, that varying degrees of placental insufficiency, i.e. reduced nutrient and $\mathrm{O}_{2}$ delivery to the fetus, may be a common factor in growth retardation and other less severe forms of fetal stress.

We also sought to evaluate the lipoprotein cholesterol status of IUGR infants, which could be an important determinant of the rate of fetal adrenal steroidogenesis $(3,24)$. Fetal zone cells of the fetal adrenal, which are the source of DS production and compose more than $75 \%$ of the mass of the fetal adrenal, have twice the capacity for LDL assimilation compared with neocortex cells (25), which produce primarily cortisol. Plasma total and LDL cholesterol levels are progressively reduced over the last few weeks of normal gestation, whereas fetal adrenal steroid production, particularly that of DS, is increased dramatically $(1,16)$. On the other hand, in circumstances wherein fetal adrenal DS production is either transiently or chronically reduced, we and others have found increases in fetal plasma LDL levels $(3,6,7$, $16,26-29)$. In the extreme case of fetal adrenal hypoplasia due to anencephaly wherein the fetal zone is primarily affected, total cholesterol and LDL cholesterol levels may be increased 200$300 \%$ above normal $(16,26,28)$. Such data suggest that the rate of uptake and utilization of LDL for use in steroidogenesis by the fetal adrenal is a quantitatively important determinant of fetal plasma cholesterol levels. We therefore expected to find marked increases in cholesterol and apo B levels in IUGR infants, who also had evidence of striking deficiencies in DS production.
Such was not the case. Rather, we found cholesterol and apo B levels to be within normal limits in IUGR infants, as have others $(27,28,30)$. In fact, the cholesterol levels in IUGR infants were reduced, although not significantly, compared with those of the control infants.

The finding of essentially normal cholesterol and apo B levels in IUGR infants, in whom there is evidence for significant impairments of adrenal DS production, could be viewed as providing evidence that there is no functional relationship between adrenal steroidogenesis and lipoprotein levels in the fetus. On the other hand, if the postulate that the fetal plasma cholesterol concentration is usually regulated, in part, by the rate at which LDL cholesterol is assimilated by the fetal adrenal for use in steroidogenesis is correct, then the failure of cholesterol and apo $B$ levels to be increased in IUGR could be interpreted as evidence for a relative deficiency of hepatic production of LDL in IUGR. Morphologic evidence for reduced numbers and size of hepatocytes (13) and reductions in plasma levels of IGF-I (18), which seems to arise primarily from the fetal liver, also are suggestive of hepatic deficiencies in IUGR. Whether either of the above speculations is correct will require further study.

Acknowledgments. The authors thank V. K. Gadi, Gerald Farrow, and Philip Robinson for technical assistance; Diane Watson for manuscript preparation; and Lisa Buckingham for graphic arts. We also thank Celso Gomez-Sanchez for his gift of cortisol antiserum.

\section{REFERENCES}

1. Parker Jr CR, Leveno K, Carr BR, Hauth J, MacDonald PC 1982 Umbilical cord plasma levels of dehydroepiandrosterone sulfate during human gestation. J Clin Endocrinol Metab 54:1216-1220

2. Masson GM 1973 Plasma oestriol concentration during normal pregnancy. J Obstet Gynaecol Br Commonw 80:201-205

3. Parker Jr CR 1992 Endocrinology of Pregnancy. In: Carr BR. Blackwell RE (eds) Textbook of Reproductive Medicine. Appleton and Lange, East Norwalk, CT, pp 17-40

4. Lindberg BS. Johansson EDB, Nilsson BA 1974 Plasma levels of unconjugated oestradiol-17B and oestriol in high risk pregnancies. Acta Obstet Gynaecol Scand [Suppl] 32:37-51

5. Bashore RA, Westlake JR 1977 Plasma unconjugated estriol values in high risk pregnancy. Am J Obstet Gynecol 128:371-379

6. Parker Jr CR, Hankins GDV, Cart BR, Leveno KJ, Gant NF, MacDonald PC 1984 The effect of hypertension in pregnant women on fetal adrenal function and fetal plasma lipoprotein-cholesterol metabolism. Am J Obstet Gynecol 150:263-269

7. Parker Jr CR, Wendel GD 1988 The effects of syphilis on endocrine function of the feto-placental unit. Am J Obstet Gynecol 159:1327-1331

8. Harlin CA, Tucker JM, Winkler C, Henson B, Parker Jr CR 1993 Altered adrenal steroid production in term infants having respiratory acidemia. Acta Endocrinol (Copenh) 128:136-139

9. Cleary RE, Depp R, Pion R 1970 Relation of $C_{19}$ steroid sulfates in cord plasma to maternal urinary estriol. Am J Obstet Gynecol 106:534-539

10. Reynolds JW, Mirkin BL 1973 Urinary steroid levels in newborn infants with intra-uterine growth retardation. J Clin Endocrinol Metab 36:576-581

11. Turnipseed MR, Bentley K, Reynolds JW 1976 Serum dehydroepiandrosterone sulfate in premature infants and infants with intrauterine growth retardation. $\mathrm{J}$ Clin Endocrinol Metab 43:1219-1225

12. Reynolds JW, Barnhart BJ, Carlson CV 1986 Feto-placental steroid metabolism in growth retarded human fetuses. Pediatr Res 20:166-168

13. Naeye RL 1965 Malnutrition: probable cause of fetal growth retardation. Arch Pathol 79:284-291

14. Seron-Ferre M, Lawrence CC, Siiteri PK, Jaffe RB 1978 Steroid production by definitive and fetal zones of the human fetal adrenal gland. J Clin Endocrinol Metab 47:603-609

15. Carr BR, Parker Jr CR, Milewich L. Porter JC, MacDonald PC, Simpson ER 1980 The role of low-density, high-density, and very low-density lipoproteins in steroidogenesis by the human fetal adrenal gland. Endocrinology 106:1854-1860

16. Parker Jr CR, Simpson ER, Bilheimer DW, Leveno K, Carr BR, MacDonald PC 1980 Inverse relationship between LDL-cholesterol and dehydroisoandrosterone sulfate in human fetal plasma. Science 208:512-514

17. Parker Jr CR, Carr BR, Simpson ER, MacDonald PC 1983 Decline in the concentration of low-density lipoprotein-cholesterol in human fetal plasma near term. Metabolism 32:919-923

18. Verhaeghe J, Van Bree R, Van Herck E, Laureys J, Bouillon R, Van Assche FA 1993 C-peptide, insulin-like growth factors $I$ and II, and insulin-like growth factor binding protein-1 in umbilical cord serum: correlations with birth weight. Am J Obstet Gynecol 169:89-97 
19. Brenner WF, Edelman DA, Hendricks $\mathrm{CH} 1976$ A standard of fetal growth for the United States of America. Am J Obstet Gynecol 126:555-564

20. Buster JE, Abraham GE 1977 Radioimmunoassay of plasma dehydroepiandrosterone sulfate. Anal Lett 5:543-551

21. Gomez-Sanchez C, Milewich L, Holland OB 1977 Radioiodinated derivatives for steroid radioimmunoassay: application to the radioimmunoassay of cortisol. J Lab Clin Med 89:902-909

22. Cassady G 1966 Plasma volume studies in low birth weight infants. Pediatrics 38:1020-1027

23. Bech K 1971 Morphology of the fetal adrenal cortex and maternal urinary oestriol excretion in pregnancy. Acta Obstet Gynaecol Scand 50:215-221

24. Carr BR, Simpson ER 1981 Lipoprotein utilization and cholesterol synthesis by the human fetal adrenal gland. Endocr Rev 2:306-326

25. Carr BR, Ohashi M, Simpson ER 1982 Low density lipoprotein binding and de novo synthesis of cholesterol in the neocortex and fetal zones of the human fetal adrenal gland. J Clin Endocrinol Metab 110:1994-1998
26. Parker Jr CR, Carr BR, Winkel CA, Casey ML, Simpson ER, MacDonald PC 1983 Hypercholesterolemia due to elevated low-density lipoprotein-cholesterol in newborns with anencephaly and adrenal atrophy. J Clin Endocrinol Metab 57:37-43

27. Andersen GE, Lous P, Friis-Hansen B 1979 Hyperlipoproteinemia in newborn infants. Acta Paediatr Scand 68:683-690

28. Lane DM, McConathy WJ 1983 Factors affecting the lipid and apolipoprotein levels of cord sera. Pediatr Res 17:83-91

29. Andrews WW, Owen J, Morrison JC, Herbert WNP, Parker Jr CR 1988 Effects of synthetic glucocorticosteroids on lipoprotein and adrenal steroid dynamics in the fetus. Proceedings of the 35th Annual Meeting of the Society of Gynecologic Investigation, Baltimore, MD (abstr 241)

30. Fosbrooke AS, Wharton BA 1973 Plasma lipids in umbilical cord blood from infants of normal and low birth weight. Biol Neonate 23:330-338 